\title{
Strong Convergence Theorems for an Implicit Iterative Algorithm for the Split Common Fixed Point Problem
}

\author{
Huimin He, ${ }^{1}$ Sanyang Liu, ${ }^{1}$ and Rudong Chen ${ }^{2}$ \\ ${ }^{1}$ School of Mathematics and Statistics, Xidian University, Xi'an 710071, China \\ ${ }^{2}$ Department of Mathematics, Tianjin Polytechnic University, Tianjin 300160, China \\ Correspondence should be addressed to Huimin He; huiminhe@126.com \\ Received 13 September 2016; Revised 11 November 2016; Accepted 21 November 2016 \\ Academic Editor: Ismat Beg
}

Copyright (c) 2016 Huimin He et al. This is an open access article distributed under the Creative Commons Attribution License, which permits unrestricted use, distribution, and reproduction in any medium, provided the original work is properly cited.

\begin{abstract}
The aim of this paper is to construct a novel implicit iterative algorithm for the split common fixed point problem for the demicontractive operators $U, T$, and $x_{n}=\alpha_{n} f\left(x_{n}\right)+\left(1-\alpha_{n}\right) U_{\lambda}\left(x_{n}-\rho_{n} A^{*}(I-T) A x_{n}\right), n \geq 0$, where $U_{\lambda}=(1-\lambda) I+\lambda U$, and we obtain the sequence which strongly converges to a solution $\hat{x}$ of this problem, and the solution $\hat{x}$ satisfies the variational inequality. $\langle\hat{x}-f(\widehat{x}), \hat{x}-z\rangle \leq 0, \forall z \in S$, where $S$ denotes the set of all solutions of the split common fixed point problem.
\end{abstract}

\section{Introduction}

The split feasibility problem (SFP) is to find a point

$$
x \in C \text { such that } A x \in Q \text {, }
$$

where $C$ is a nonempty closed convex subset of a Hilbert space $H_{1}$, Q is a nonempty closed convex subset of a Hilbert space $\mathrm{H}_{2}$, and $\mathrm{A}: \mathrm{H}_{1} \rightarrow \mathrm{H}_{2}$ is a bounded linear operator. 1994.

This problem was proposed by Censor and Elfving [1] in

Since the SFP can extensively be applied in fields such as intensity-modulated radiation therapy, signal processing, and image reconstruction, then the SFP has received so much attention by so many scholars; see [2-23].

In 1994, Censor and Elfving [1] proposed the original algorithm in $R^{n}$,

$$
x_{n+1}=A^{-1} P_{\mathrm{Q}} P_{A(C)} A x_{n},
$$

where $C$ and $Q$ are nonempty closed convex subsets of $R^{n}, A$ in the finite-dimensional $R^{n}$ is a $n \times n$ matrix, and $P_{Q}$ is the projection operator from $\mathrm{H}_{2}$ onto $Q$.

As we know, the computation of the inverse $A^{-1}$ is not easy if the inverse of $A$ existed. So, the algorithm (2) does not become popular.
In 2002 and 2004, Byrne [2, 3] gave the so-called CQ algorithm as follows:

$$
x_{n+1}=P_{C}\left(x_{n}-\gamma A^{*}\left(I-P_{\mathrm{Q}}\right) A x_{n}\right), \quad n \geq 0,
$$

where $0<\gamma<2 / \rho$ with $\rho$ taken as the largest eigenvalue of the operator $A^{*} A$ and $P_{C}$ and $P_{Q}$ denote the projection operators from $H_{1}$ and $H_{2}$ onto the sets $C, Q$, respectively.

For the stepsize of algorithm (3) is fixed and closely related to spectral radius of $A^{*} A$, then the projection operators $P_{\mathrm{C}}$ and $P_{\mathrm{Q}}$ are not easily calculated usually.

The split common fixed point problem (SCFP) is to find a point

$$
x \in \operatorname{Fix}(U) \quad \text { such that } A x \in \operatorname{Fix}(T) \text {, }
$$

where $U: H_{1} \rightarrow H_{1}$ and $T: H_{2} \rightarrow H_{2}$, and $\operatorname{Fix}(U)$ and Fix $(T)$ denote the fixed point sets of $U$ and $T$.

This problem was proposed by Censor and Segal [12] in 2009. Note that the SCFP is closely related to SFP and it is a particular case of SFP.

In 2009, Censor and Segal [12] introduced the original algorithm for directed operators as follows:

$$
x_{n+1}=U\left(x_{n}-\rho A^{*}(I-T) A x_{n}\right), \quad n \geq 0,
$$

where the step size $\rho$ satisfies $0<\rho<2 /\|A\|^{2}$, and they obtained that $\left\{x_{n}\right\}$ weakly converges to a solution of the SCFP 
(4) if the solution of SCFP exists. But it is obvious that the choice of the step size $\rho$ depends on the norm of operator, $A$, which is the disadvantage of this algorithm.

The next two years, some extension results on the operators are obtained, such as Moudafi (2010) [24], Moudafi (2011) [25], and Wang and $\mathrm{Xu}$ (2011) [14].

In order to overcome this disadvantage, Cui and Wang [26] proposed the following algorithm in 2014:

$$
x_{n+1}=U_{\lambda}\left(x_{n}-\rho_{n} A^{*}(I-T) A x_{n}\right), \quad n \geq 0,
$$

where $U_{\lambda}=(1-\lambda) I+\lambda U$ and the step size $\rho_{n}$ is chosen by the following way:

$$
\rho_{n}= \begin{cases}\frac{(1-\tau)\left\|(I-T) A x_{n}\right\|^{2}}{2\left\|A^{*}(I-T) A x_{n}\right\|^{2}}, & A x_{n} \neq T\left(A x_{n}\right), \\ 0, & \text { otherwise }\end{cases}
$$

and they proved that the sequence $\left\{x_{n}\right\}$ converges weakly to a solution of the SCFP (4). Note that the advantage of this algorithm is that the step size $\rho_{n}$ searches automatically and does not depend on the norm of operator $A$.

Recently, Byrne et al. [27] introduced the split common null point problem (SCNPP) for set-valued maximal monotone mappings in Hilbert spaces. Given set-valued mappings $B_{i}: H_{1} \rightarrow 2^{H_{1}}, 1 \leq i \leq p$, and $F_{j}: H_{2} \rightarrow 2^{H_{2}}, 1 \leq j \leq r$, respectively, and the bounded linear operators $A_{j}: H_{1} \rightarrow$ $H_{2}, 1 \leq j \leq r$, the SCNPP is formulated as follows:

$$
\begin{array}{cl}
\text { find } & x \in H_{1} \\
\text { such that } & 0 \in \bigcap_{i=1}^{p} B_{i}(x) \\
\text { such that } & y_{j}=A_{j}(x) \in H_{2} \\
& \text { solve } 0 \in \bigcap_{j=1}^{r} F_{J}\left(y_{j}\right) .
\end{array}
$$

As we know, the SCNPP generalizes the split common fixed point problem and the split variational inequality problem $[28,29]$.

Motivated by the viscosity idea of [30], in this paper, we construct a novel algorithm for demicontractive operators to approximate the solution of the SCFP (4), that is, the following implicit iterative algorithm:

$$
\begin{array}{r}
x_{n}=\alpha_{n} f\left(x_{n}\right)+\left(1-\alpha_{n}\right) U_{\lambda}\left(x_{n}-\rho_{n} A^{*}(I-T) A x_{n}\right), \\
n \geq 0,
\end{array}
$$

where $U_{\lambda}=(1-\lambda) I+\lambda U$ and the step size $\rho_{n}$ is also chosen as (7).

The research highlight of this paper is that the strong convergence of the SCFP (4) is constructed; that is to say the sequence $\left\{x_{n}\right\}$ generated by (9) converges strongly to a solution of the SCFP.

\section{Preliminaries}

Throughout this paper, we denote the set of all solutions of the SCFP (4) by $S$. We use $x_{n} \rightarrow x$ to indicate that $\left\{x_{n}\right\}$ converges weakly to $x$. Similarly, $x_{n} \rightarrow x$ symbolizes the sequence $\left\{x_{n}\right\}$ which converges strongly to $x$.

Let $H, H_{1}$, and $H_{2}$ be Hilbert spaces endowed with the inner product $\langle\cdot, \cdot\rangle$ and norm $\|\cdot\|$, and $C$ and $Q$ are nonempty closed convex subsets of $H_{1}$ and $H_{2}$, respectively.

Some concepts and lemmas are given in the following and they are useful in proving our main results.

Definition 1. A operator $T: H \rightarrow H$ is said to be

(i) nonexpansive if

$$
\|T x-T y\| \leq\|x-z\|, \quad \forall x, y \in H
$$

(ii) quasi-nonexpansive if

$$
\|T x-z\| \leq\|x-z\|, \quad \forall x \in H, \forall z \in \operatorname{Fix}(T)
$$

(iii) directed if

$$
\langle z-T x, x-T x\rangle \leq 0, \quad \forall x \in H, \forall z \in \operatorname{Fix}(T)
$$

(iv) $\tau$-demicontractive with $\tau<1$ if

$$
\begin{aligned}
\|T x-z\|^{2} \leq\|x-z\|^{2}+\tau \| x-T & \\
& \\
\forall x \|^{2} & \\
&
\end{aligned}
$$

Note that (12) is equivalent to

$$
\begin{aligned}
\|z-T x\|^{2}+\|x-T x\|^{2}-\|x-z\|^{2} & \leq 0, \\
\forall x & \in H, \forall z \in \operatorname{Fix}(T)
\end{aligned}
$$

Definition 2. Let $T: H \rightarrow H$ be an operator, then $I-T$ is said to be demiclosed at zero, if for any $\left\{x_{n}\right\}$ in $H$, the following implication holds

$$
\begin{array}{r}
x_{n} \longrightarrow x \\
(I-T) x_{n} \longrightarrow 0 \\
\Downarrow \\
x=T x
\end{array}
$$

As we know, the nonexpansive mappings are demiclosed at zero [31].

Definition 3. Let $C$ be a nonempty closed convex subset of a Hilbert space $H$, the metric (nearest point) projection $P_{C}$ from $H$ to $C$ is defined as follows: Given $x \in H, P_{C} x$ is the only point in $C$ with the property

$$
\left\|x-P_{C} x\right\|=\inf \{\|x-y\|: y \in C\} .
$$

Lemma 4 (see [32]). Let $C$ be a nonempty closed convex subset of a Hilbert space $H, P_{C}$ is a nonexpansive mapping from $H$ onto $C$ and is characterized as: Given $x \in H$, there holds the inequality

$$
\left\langle x-P_{C} x, y-P_{C} x\right\rangle \leq 0, \quad \forall y \in C .
$$



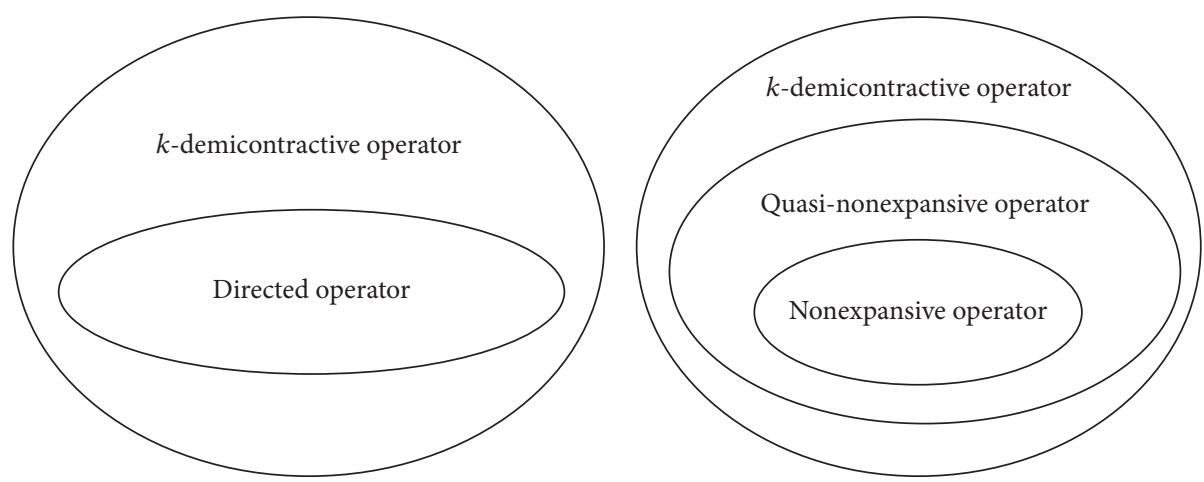

FIGURE 1: The relations of $k$-demicontractive operator, directed operator, quasi-nonexpansive operator, and nonexpansive operator.

Lemma 5 (see [32]). Let $H$ be a Hilbert space, then the following inequality holds,

$$
\|x+y\|^{2} \leq\|x\|^{2}+2\langle y, x+y\rangle, \quad \forall x, y \in H .
$$

Lemma 6 (Cui and Wang [26]). Let $A: H_{1} \rightarrow H_{2}$ be a bounded linear operator and $\mathrm{T}: \mathrm{H}_{2} \rightarrow \mathrm{H}_{2}$ a $\tau$-demicontractive operator with $\tau<1$. If $A^{-1}$ Fix $(T) \neq \emptyset$, then

(a) $(I-T) A x=0 \Leftrightarrow A^{*}(I-T) A x=0, \forall x \in H_{1}$.

(b) In addition, for $z \in A^{-1}$ Fix (T)

$$
\begin{aligned}
\| x & -\rho A^{*}(I-T) A x-z \|^{2} \\
& \leq\|x-z\|^{2}-\frac{(1-\tau)^{2}}{4} \frac{\|(I-T) A x\|^{4}}{\left\|A^{*}(I-T) A x\right\|^{2}}
\end{aligned}
$$

where $x \in H_{1}, A x \neq T(A x)$ and

$$
\rho:=\frac{1-\tau}{2} \frac{\|(I-T) A x\|^{2}}{\left\|A^{*}(I-T) A x\right\|^{2}}
$$

Lemma 7 (Cui and Wang [26]). Let $U: H_{1} \rightarrow H_{1}$ be a $k$ demicontractive operator with $k<1$. Denote $U_{\lambda}:=(1-\lambda) I+$ $\lambda U$ for $\lambda \in(0,1-k)$. Then for any $x \in H_{1}$ and $z \in$ Fix $(U)$,

$$
\left\|U_{\lambda} x-z\right\|^{2} \leq\|x-z\|^{2}-\lambda(1-k-\lambda)\|x-U x\|^{2} .
$$

\section{Main Results}

Proposition 8. Based on the definitions in preliminaries, the classes of $k$-demicontractive operators, directed operators, quasi-nonexpansive operators, and nonexpansive operators have close relations. We can visually use the following Venn diagram (Figure 1) to denote their relations.

Proof. From Definition 1, the following conclusion is obtained easily.

(i) The nonexpansive operator is quasi-nonexpansive operator.

(ii) The quasi-nonexpansive operator is 0 -demicontractive operator. (iii) The directed operator is -1-demicontractive operator.

Next, we give the novel implicit algorithm to solve the SCFP (4) for demicontractive operators. In the sequel, the assumptions are given as follows:

(i) $U: H_{1} \rightarrow H_{1}$ is a $k$-demicontractive operator with $k<1$.

(ii) $\mathrm{T}: \mathrm{H}_{2} \rightarrow \mathrm{H}_{2}$ is a $\tau$-demicontractive operator with $\tau<1$.

(iii) Both $I-U$ and $I-T$ are demiclosed at zero.

Algorithm 9. Choose an initial guess $x_{0} \in H_{1}$ arbitrarily. Let $f$ be a fixed contraction on $\operatorname{Fix}(U)$ with coefficient $\alpha(0<\alpha<$ $1), \lambda \in(0,1-\tau)$. Assume that the $n$th iteration $x_{n}$ has been constructed. Then the $(n+1)$ th iteration is via the following formula:

$$
\begin{aligned}
x_{n}= & \alpha_{n} f\left(x_{n}\right) \\
& +\left(1-\alpha_{n}\right) U_{\lambda}\left(x_{n}-\rho_{n} A^{*}(I-T) A x_{n}\right),
\end{aligned}
$$

$n \geq 0$,

where $A^{*}$ is the adjoint of bounded linear operator $A$ and the step size $\rho_{n}$ is chosen in the following way:

$$
\rho_{n}= \begin{cases}\frac{(1-\tau)\left\|(I-T) A x_{n}\right\|^{2}}{2\left\|A^{*}(I-T) A x_{n}\right\|^{2}}, & A x_{n} \neq T\left(A x_{n}\right) \\ 0, & \text { otherwise. }\end{cases}
$$

Theorem 10. Assume the solution set of the SCFP (4) $S \neq \emptyset$. If $\alpha_{n} \in(0,1)$ satisfies $\lim _{n \rightarrow \infty} \alpha_{n}=0$ and $\sum_{n=0}^{\infty} \alpha_{n}=\infty$, then the sequence $\left\{x_{n}\right\}$ generated by implicit algorithm (22) converges strongly to a point $\hat{x} \in S$, and $\hat{x}=P_{S} f(\hat{x})$; that is, $\hat{x}$ satisfies the following variational inequality:

$$
\langle\widehat{x}-f(\widehat{x}), \widehat{x}-z\rangle \leq 0, \quad \forall z \in S .
$$

Proof. The proof is divided into three steps.

Step 1. We show that $\left\{x_{n}\right\}$ is bounded. 
Denote $y_{n}:=x_{n}-\rho_{n} A^{*}(I-T) A x_{n}$ and take $z \in S$; it follows from (22) that

$$
\begin{aligned}
\left\|x_{n}-z\right\|= & \left\|\alpha_{n}\left(f\left(x_{n}\right)-z\right)+\left(1-\alpha_{n}\right)\left(U_{\lambda} y_{n}-z\right)\right\| \\
\leq & \alpha_{n}\left\|f\left(x_{n}\right)-f(z)\right\|+\left(1-\alpha_{n}\right)\left\|U_{\lambda} y_{n}-z\right\| \\
& +\alpha_{n}\|f(z)-z\| \\
\leq & \alpha \alpha_{n}\left\|x_{n}-z\right\|+\left(1-\alpha_{n}\right)\left\|U_{\lambda} y_{n}-z\right\| \\
& +\alpha_{n}\|f(z)-z\| .
\end{aligned}
$$

(i) If $\rho_{n}=0$. Then $y_{n}=x_{n}$; from (21), we get

$$
\left\|U_{\lambda} x_{n}-z\right\| \leq\left\|x_{n}-z\right\| \text {. }
$$

Thus

$$
\begin{aligned}
\left\|x_{n}-z\right\| \leq & \alpha \alpha_{n}\left\|x_{n}-z\right\|+\left(1-\alpha_{n}\right)\left\|x_{n}-z\right\| \\
& +\alpha_{n}\|f(z)-z\| .
\end{aligned}
$$

Hence

$$
\left\|x_{n}-z\right\| \leq \frac{1}{1-\alpha}\|f(z)-z\| .
$$

So, $\left\{x_{n}\right\}$ is bounded, so is $\left\{f\left(x_{n}\right)\right\}$.

(ii) If $\rho_{n} \neq 0$. It follows from (19) and (21) that we get

$$
\begin{aligned}
\left\|U_{\lambda} y_{n}-z\right\|^{2} \leq & \left\|y_{n}-z\right\|^{2}-\lambda(1-\lambda-k)\left\|y_{n}-U y_{n}\right\|^{2} \\
= & \left\|x_{n}-\rho_{n} A^{*}(I-T) A x_{n}-z\right\|^{2} \\
& -\lambda(1-\lambda-k)\left\|y_{n}-U y_{n}\right\|^{2} \\
\leq & \left\|x_{n}-z\right\|^{2} \\
& -\frac{(1-\tau)^{2}}{4} \frac{\left\|(I-T) A x_{n}\right\|^{4}}{\left\|A^{*}(I-T) A x_{n}\right\|^{2}} \\
& -\lambda(1-\lambda-k)\left\|y_{n}-U y_{n}\right\|^{2} .
\end{aligned}
$$

Thus,

$$
\left\|U_{\lambda} y_{n}-z\right\| \leq\left\|x_{n}-z\right\| .
$$

Combining with (30) and (25), we get (28). So, $\left\{x_{n}\right\}$ is bounded, so is $\left\{f\left(x_{n}\right)\right\}$.

Step 2. We show that there exists a subsequence $\left\{x_{n_{j}}\right\} \subseteq\left\{x_{n}\right\}$ such that $x_{n_{j}} \rightarrow \hat{x}$ as $j \rightarrow \infty$, and $\hat{x} \in S$ solves the variational inequality (24).

By the reflexivity of Hilbert space $H_{1}$ and the boundedness of $\left\{x_{n}\right\}$, there exists a weakly convergence subsequence $\left\{x_{n_{j}}\right\} \subseteq\left\{x_{n}\right\}$ such that $x_{n_{j}} \rightarrow \widehat{x}$, as $j \rightarrow \infty$.

First, we show that $x_{n_{j}} \rightarrow \widehat{x}$, as $j \rightarrow \infty$.

Next, we denote $x_{n_{j}}$ by $x_{j}$. (i) If $\rho_{n_{j}}=0$. From (18) and (21), we have

$$
\begin{aligned}
&\left\|x_{j}-\hat{x}\right\|^{2} \\
& \leq\left(1-\alpha_{j}\right)\left\|U_{\lambda} x_{j}-\hat{x}\right\|^{2} \\
&+2 \alpha_{j}\left\langle f\left(x_{j}\right)-\hat{x}, x_{j}-\hat{x}\right\rangle \\
& \leq\left(1-\alpha_{j}\right)\left[\left\|x_{j}-\hat{x}\right\|^{2}-\lambda(1-k-\lambda)\left\|x_{j}-U x_{j}\right\|^{2}\right] \\
&+2 \alpha_{j}\left\langle f\left(x_{j}\right)-\hat{x}, x_{j}-\hat{x}\right\rangle \\
& \leq\left(1-\alpha_{j}\right)\left\|x_{j}-\hat{x}\right\|^{2}+2 \alpha_{j}\left\langle f\left(x_{j}\right)-\hat{x}, x_{j}-\hat{x}\right\rangle .
\end{aligned}
$$

Hence

$$
\begin{aligned}
\left\|x_{j}-\hat{x}\right\|^{2} \leq & 2\left\langle f\left(x_{j}\right)-\hat{x}, x_{j}-\hat{x}\right\rangle \\
\leq & 2\left\langle f\left(x_{j}\right)-f(\widehat{x}), x_{j}-\hat{x}\right\rangle \\
& +2\left\langle f(\hat{x})-\hat{x}, x_{j}-\hat{x}\right\rangle \\
\leq & 2 \alpha\left\|x_{j}-\hat{x}\right\|^{2}+2\left\langle f(\hat{x})-\hat{x}, x_{j}-\hat{x}\right\rangle .
\end{aligned}
$$

So

$$
\left\|x_{j}-\widehat{x}\right\|^{2} \leq \frac{2}{1-2 \alpha}\left\langle f(\hat{x})-\widehat{x}, x_{j}-\widehat{x}\right\rangle .
$$

For $\left\{x_{j}\right\} \rightarrow \widehat{x}$ as $j \rightarrow \infty$, the above inequality implies that

$$
x_{j} \longrightarrow \widehat{x} \quad \text { as } j \longrightarrow \infty .
$$

(ii) If $\rho_{n_{j}} \neq 0$. From (18), (19) and (21), we have

$$
\begin{aligned}
& \left\|x_{j}-\hat{x}\right\|^{2} \leq\left(1-\alpha_{j}\right)\left\|U_{\lambda} y_{j}-\hat{x}\right\|^{2} \\
& +2 \alpha_{j}\left\langle f\left(x_{j}\right)-\hat{x}, x_{n+1}-\hat{x}\right\rangle \leq\left(1-\alpha_{j}\right) \\
& \cdot\left(\left\|y_{j}-\hat{x}\right\|^{2}-\lambda(1-k-\lambda)\left\|y_{j}-U y_{j}\right\|^{2}\right) \\
& +2 \alpha_{j}\left\langle f\left(x_{j}\right)-\hat{x}, x_{n+1}-\hat{x}\right\rangle \leq\left(1-\alpha_{j}\right) \\
& \cdot\left(\left\|x_{j}-\hat{x}\right\|^{2}-\frac{(1-\tau)^{2}}{4} \frac{\left\|(I-T) A x_{j}\right\|^{4}}{\left\|A^{*}(I-T) A x_{j}\right\|^{2}}\right) \\
& +\left(1-\alpha_{j}\right) \lambda(1-k-\lambda)\left\|y_{j}-U y_{j}\right\|^{2} \\
& +2 \alpha_{j}\left\langle f\left(x_{j}\right)-\hat{x}, x_{j}-\hat{x}\right\rangle \leq\left(1-\alpha_{j}\right)\left\|x_{j}-\hat{x}\right\|^{2} \\
& +2 \alpha_{j}\left\langle f\left(x_{j}\right)-\hat{x}, x_{j}-\hat{x}\right\rangle .
\end{aligned}
$$

Then, (33) is obtained. By the similar proofs of the case of $\rho_{n_{j}}=0$, we conclude that

$$
x_{j} \longrightarrow \hat{x} \quad \text { as } j \longrightarrow \infty \text {. }
$$


Second, we show that $\hat{x} \in S$.

(i) If $\rho_{n_{j}}=0$. From (31), we get

$$
\begin{aligned}
& \lambda(1-k-\lambda)\left\|x_{j}-U x_{j}\right\|^{2} \\
& \quad \leq \alpha_{j}\left\langle f\left(x_{j}\right)-\widehat{x}, x_{j}-\widehat{x}\right\rangle-\alpha_{j}\left\|x_{j}-\hat{x}\right\|^{2} \\
& \quad \leq \alpha_{j}\left\langle f\left(x_{j}\right)-\hat{x}, x_{j}-\hat{x}\right\rangle .
\end{aligned}
$$

Hence

$$
\left\|x_{j}-U x_{j}\right\| \longrightarrow 0 \quad \text { as } j \longrightarrow \infty \text {. }
$$

For the case $\rho_{n_{j}}=0$, then it is clear we obtain

$$
\left\|(I-T) A x_{j}\right\| \longrightarrow 0 \quad \text { as } j \longrightarrow \infty .
$$

From (37) and the demiclosedness of $I-U$ at zero, then

$$
\widehat{x} \in \operatorname{Fix}(U) .
$$

Since $A$ is bounded linear operator, then $A$ is weak continuity; then

$$
\begin{gathered}
x_{j} \rightarrow \widehat{x} \Longrightarrow \\
A x_{j} \rightarrow A \hat{x}, \quad \text { as } j \longrightarrow \infty .
\end{gathered}
$$

From (39) and the demiclosedness of $I-T$ at zero, then

$$
A \hat{x} \in \operatorname{Fix}(T) .
$$

Hence, $\widehat{x} \in S$ by (40) and (42).

(ii) If $\rho_{n_{j}} \neq 0$. From (35), we get

$$
\begin{aligned}
& \lambda(1-k-\lambda)\left\|y_{j}-U y_{j}\right\|^{2} \\
& \quad+\frac{(1-\tau)^{2}}{4} \frac{\left\|(I-T) A x_{j}\right\|^{4}}{\left\|A^{*}(I-T) A x_{j}\right\|^{2}} \\
& \quad \leq 2 \frac{\alpha_{j}}{1-\alpha_{j}}\left\langle f\left(x_{j}\right)-\hat{x}, x_{j}-\hat{x}\right\rangle-\alpha_{j}\left\|x_{j}-\hat{x}\right\|^{2} \\
& \quad \leq 2 \frac{\alpha_{j}}{1-\alpha_{j}}\left\langle f\left(x_{j}\right)-\hat{x}, x_{j}-\hat{x}\right\rangle .
\end{aligned}
$$

So, we have

$$
\begin{aligned}
0 \leq & \lambda(1-k-\lambda)\left\|y_{j}-U y_{j}\right\|^{2} \\
& \leq 2 \frac{\alpha_{j}}{1-\alpha_{j}}\left\langle f\left(x_{j}\right)-\hat{x}, x_{j}-\hat{x}\right\rangle, \\
\frac{(1-\tau)^{2}}{4} \frac{\left\|(I-T) A x_{j}\right\|^{4}}{\left\|A^{*}(I-T) A x_{j}\right\|^{2}} & \\
& \leq 2 \frac{\alpha_{j}}{1-\alpha_{j}}\left\langle f\left(x_{j}\right)-\hat{x}, x_{j}-\hat{x}\right\rangle .
\end{aligned}
$$

Take $j \rightarrow \infty$, we have

$$
\begin{array}{r}
\left\|y_{j}-U y_{j}\right\| \longrightarrow 0 \quad \text { as } j \longrightarrow \infty, \\
\frac{\left\|(I-T) A x_{j}\right\|^{2}}{\left\|A^{*}(I-T) A x_{j}\right\|} \longrightarrow 0 \quad \text { as } j \longrightarrow \infty .
\end{array}
$$

Moreover,

$$
\begin{aligned}
\left\|(I-T) A x_{j}\right\|= & \|A\| \cdot \frac{\left\|(I-T) A x_{j}\right\|}{\|A\|} \\
= & \|A\| \\
& \cdot\left\|(I-T) A x_{j}\right\| \frac{\left\|(I-T) A x_{j}\right\|}{\|A\|\left\|(I-T) A x_{j}\right\|} \\
\leq & \|A\| \\
& \cdot\left\|(I-T) A x_{j}\right\| \frac{\left\|(I-T) A x_{j}\right\|}{\left\|A^{*}(I-T) A x_{j}\right\|} \\
= & \|A\| \frac{\left\|(I-T) A x_{j}\right\|^{2}}{\left\|A^{*}(I-T) A x_{j}\right\|} .
\end{aligned}
$$

Hence, from (46)

$$
\left\|(I-T) A x_{j}\right\| \longrightarrow 0, \quad \text { as } j \longrightarrow \infty .
$$

By $y_{j}:=x_{j}-\rho_{j} A^{*}(I-T) A x_{j}$, we have

$$
\begin{aligned}
\left\|x_{j}-y_{j}\right\| & =\rho_{j}\left\|A^{*}(I-T) A x_{j}\right\| \\
& =\frac{1-\tau}{2} \frac{\left\|(I-T) A x_{j}\right\|^{2}}{\left\|A^{*}(I-T) A x_{j}\right\|} .
\end{aligned}
$$

So,

$$
\left\|x_{j}-y_{j}\right\| \longrightarrow 0, \text { as } j \longrightarrow \infty .
$$

For $x_{j} \rightarrow \widehat{x}$, then $y_{j} \rightarrow \widehat{x}$ by (50).

From (45) and the demiclosedness of $I-U$ at zero, then

$$
\widehat{x} \in \operatorname{Fix}(U) .
$$

From (48) and the demiclosedness of $I-T$ at zero, then

$$
A \widehat{x} \in \operatorname{Fix}(T) .
$$

So, $\widehat{x} \in S$ by (51) and (52). (24).

Third, we show that $\widehat{x} \in S$ solves the variational inequality Indeed, from (22), we get

$$
\begin{aligned}
(I-f) x_{j} \\
\quad=-\frac{1-\alpha_{j}}{\alpha_{j}}\left[x_{j}-U_{\lambda}\left(x_{j}-\rho_{n} A^{*}(I-T) A x_{j}\right)\right] \\
=-\frac{1-\alpha_{j}}{\alpha_{j}}\left(x_{j}-U_{\lambda} y_{j}\right) .
\end{aligned}
$$


The above equality and (30) imply that

$$
\begin{gathered}
\left\langle(I-f) x_{j}, x_{j}-z\right\rangle=-\frac{1-\alpha_{j}}{\alpha_{j}}\left\langle x_{j}-U_{\lambda} y_{j}, x_{j}-z\right\rangle \\
=-\frac{1-\alpha_{j}}{\alpha_{j}}\left\langle x_{j}-z-\left(U_{\lambda} y_{j}-z\right), x_{j}-z\right\rangle \leq 0 .
\end{gathered}
$$

Since

$$
\begin{aligned}
& \left\langle x_{j}-z-\left(U_{\lambda} y_{j}-z\right), x_{j}-z\right\rangle \\
& =\left\|x_{j}-z\right\|^{2}-\left\langle U_{\lambda} y_{j}-z, x_{j}-z\right\rangle \\
& \geq\left\|x_{j}-z\right\|^{2}-\left\|U_{\lambda} y_{j}-z\right\| \cdot\left\|x_{j}-z\right\| \\
& \geq\left\|x_{j}-z\right\|^{2}-\left\|x_{j}-z\right\| \cdot\left\|x_{j}-z\right\|=0,
\end{aligned}
$$

take the limit through $j \rightarrow \infty$ and we obtain

$$
\langle\widehat{x}-f(\widehat{x}), \widehat{x}-z\rangle \leq 0, \quad \forall z \in S .
$$

Step 3. We show that $x_{n} \rightarrow \widehat{x}$ as $n \rightarrow \infty$.

To show that $x_{n} \rightarrow \hat{x}$ as $n \rightarrow \infty$, we only need to show that any subsequence of $\left\{x_{n}\right\}$ converges strongly to $\hat{x}$.

Assuming the above conclusion does not hold, that is to say, there exists another subsequence $\left\{x_{n_{k}}\right\} \subseteq\left\{x_{n}\right\}$, which converges strongly to $\tilde{x} \neq \hat{x}$ as $k \rightarrow \infty$. Similarly, we know $\tilde{x} \in S$ solves the variational inequality

$$
\langle\widetilde{x}-f(\tilde{x}), \tilde{x}-z\rangle \leq 0, \quad \forall z \in S .
$$

Replacing $z \in S$ with $\tilde{x} \in S$ in (56) and replacing $z \in S$ with $\widehat{x} \in S$ in (57), we obtain

$$
\begin{aligned}
& \langle\hat{x}-f(\widehat{x}), \widehat{x}-\tilde{x}\rangle \leq 0, \\
& \langle\widetilde{x}-f(\tilde{x}), \tilde{x}-\widehat{x}\rangle \leq 0 .
\end{aligned}
$$

Adding up the above variational inequality yields

$$
\begin{aligned}
(1-\alpha)\|\widehat{x}-\tilde{x}\|^{2} & \leq\langle\widehat{x}-\tilde{x},(I-f) \hat{x}-(I-f) \tilde{x}\rangle \\
& \leq 0
\end{aligned}
$$

Thus $\hat{x}=\tilde{x}$. This is contradicting with the assumption $\widehat{x} \neq \tilde{x}$, so $\left\{x_{n}\right\}$ converges strongly to $\hat{x}$.

The proof is completed.

\section{Applications}

In this section, we consider some special cases as the applications of Theorem 10 .

Based on the relations of $k$-demicontractive operators, directed operators, and quasi-nonexpansive operators (Proposition 8), the following corollaries are obtained easily.

Corollary 11. Let $U: H_{1} \rightarrow H_{1}$ and $T: H_{2} \rightarrow H_{2}$ be quasinonexpansive operators and $I-U$ and $I-T$ be demiclosed at zero. Assume the SCFP (4) is consistent $(S \neq \emptyset)$. If $\alpha_{n} \in(0,1)$ satisfies $\lim _{n \rightarrow \infty} \alpha_{n}=0$ and $\sum_{n=0}^{\infty} \alpha_{n}=\infty$, then the sequence $\left\{x_{n}\right\}$ generated by implicit algorithm (22) converges strongly to a point $\widehat{x} \in S$, and $\hat{x}=P_{S} f(\widehat{x})$; that is, $\widehat{x}$ satisfies the following variational inequality (24).

Corollary 12. Let $U: H_{1} \rightarrow H_{1}$ and $T: H_{2} \rightarrow H_{2}$ be directed operators and $I-U$ and $I-T$ be demiclosed at zero. Assume the SCFP (4) is consistent $(S \neq \emptyset)$. If $\alpha_{n} \in(0,1)$ satisfies $\lim _{n \rightarrow \infty} \alpha_{n}=0$ and $\sum_{n=0}^{\infty} \alpha_{n}=\infty$, then the sequence $\left\{x_{n}\right\}$ generated by implicit algorithm (22) converges strongly to a point $\hat{x} \in S$, and $\hat{x}=P_{S} f(\widehat{x})$; that is, $\widehat{x}$ satisfies the following variational inequality (24).

Corollary 13. Let $U: H_{1} \rightarrow H_{1}$ be a directed operator, $T$ : $\mathrm{H}_{2} \rightarrow \mathrm{H}_{2}$ be a quasi-nonexpansive operator, and $\mathrm{I}-U$ and I $-T$ be demiclosed at zero. Assume the SCFP (4) is consistent $(S \neq \emptyset)$. If $\alpha_{n} \in(0,1)$ satisfies $\lim _{n \rightarrow \infty} \alpha_{n}=0$ and $\sum_{n=0}^{\infty} \alpha_{n}=$ $\infty$, then the sequence $\left\{x_{n}\right\}$ generated by implicit algorithm (22) converges strongly to a point $\hat{x} \in S$, and $\hat{x}=P_{S} f(\widehat{x})$; that is, $\widehat{x}$ satisfies the following variational inequality (24).

Corollary 14. Let $U: H_{1} \rightarrow H_{1}$ be a directed operator, $\mathrm{T}: \mathrm{H}_{2} \rightarrow \mathrm{H}_{2}$ be a $\tau$-demicontractive operator, and $\mathrm{I}-\mathrm{U}$ and $I-T$ be demiclosed at zero. Assume the SCFP (4) is consistent $(S \neq \emptyset)$. If $\alpha_{n} \in(0,1)$ satisfies $\lim _{n \rightarrow \infty} \alpha_{n}=0$ and $\sum_{n=0}^{\infty} \alpha_{n}=$ $\infty$, then the sequence $\left\{x_{n}\right\}$ generated by implicit algorithm (22) converges strongly to a point $\hat{x} \in S$, and $\hat{x}=P_{S} f(\widehat{x})$; that is, $\hat{x}$ satisfies the following variational inequality (24).

Corollary 15. Let $U: H_{1} \rightarrow H_{1}$ be a quasi-nonexpansive operator, $\mathrm{T}: \mathrm{H}_{2} \rightarrow \mathrm{H}_{2}$ be a $\tau$-demicontractive operator, and $I-U$ and $I-T$ be demiclosed at zero. Assume the SCFP (4) is consistent $(S \neq \emptyset)$. If $\alpha_{n} \in(0,1)$ satisfies $\lim _{n \rightarrow \infty} \alpha_{n}=0$ and $\sum_{n=0}^{\infty} \alpha_{n}=\infty$, then the sequence $\left\{x_{n}\right\}$ generated by implicit algorithm (22) converges strongly to a point $\hat{x} \in S$, and $\hat{x}=$ $P_{S} f(\widehat{x})$; that is, $\widehat{x}$ satisfies the following variational inequality (24).

\section{Conclusions}

In this paper, the research highlights that the strong convergence of the SCFP (4) is constructed. We construct a novel implicit algorithm for demicontractive operator to solve the split common fixed points problem SCFP, and we prove that the sequence $\left\{x_{n}\right\}$ strongly converges to a solution of the SCFP. These results further complete the theory of the SCFP, and some relevant work can be extended in the future.

\section{Competing Interests}

The authors declare that they have no competing interests.

\section{Authors' Contributions}

This work was carried out by the three authors, in collaboration. Moreover, the three authors have read and approved the final manuscript. 


\section{Acknowledgments}

This paper was funded by Fundamental Research Funds for the Central Universities (no. JB150703), National Science Foundation for Young Scientists of China (no. 11501431), and National Science Foundation for Tian Yuan of China (no. 11426167).

\section{References}

[1] Y. Censor and T. Elfving, "A multiprojection algorithm using Bregman projections in a product space," Numerical Algorithms, vol. 8, no. 2-4, pp. 221-239, 1994.

[2] C. Byrne, "Iterative oblique projection onto convex sets and the split feasibility problem," Inverse Problems, vol. 18, no. 2, pp. 441453, 2002.

[3] C. Byrne, "A unified treatment of some iterative algorithms in signal processing and image reconstruction," Inverse Problems, vol. 20, no. 1, pp. 103-120, 2004.

[4] Q. Yang, "The relaxed CQ algorithm solving the split feasibility problem," Inverse Problems, vol. 20, no. 4, pp. 1261-1266, 2004.

[5] Y. Censor, T. Bortfeld, B. Martin, and A. Trofimov, "A unified approach for inversion problems in intensity-modulated radiation therapy," Physics in Medicine and Biology, vol. 51, no. 10, pp. 2353-2365, 2006.

[6] Y. Censor, T. Elfving, N. Kopf, and T. Bortfeld, “The multiplesets split feasibility problem and its applications for inverse problems," Inverse Problems, vol. 21, no. 6, pp. 2071-2084, 2005.

[7] B. Qu and N. Xiu, "A note on the CQ algorithm for the split feasibility problem," Inverse Problems, vol. 21, no. 5, pp. 1655$1665,2005$.

[8] J. Zhao and Q. Yang, "Several solution methods for the split feasibility problem," Inverse Problems, vol. 21, no. 5, pp. 17911799, 2005.

[9] H. K. Xu, "A variable Krasnosel'skii-Mann algorithm and the multiple-set split feasibility problem," Inverse Problems, vol. 22, no. 6, pp. 2021-2034, 2006.

[10] Q. W. Fan, W. Wu, and J. M. Zurada, "Convergence of batch gradient learning with smoothing regularization and adaptive momentum for neural networks," Springer Plus, vol. 5, no. 295, pp. 1-17, 2016.

[11] B. Qu and N. Xiu, "A new halfspace-relaxation projection method for the split feasibility problem," Linear Algebra and Its Applications, vol. 428, no. 5-6, pp. 1218-1229, 2008.

[12] Y. Censor and A. Segal, "The split common fixed point problem for directed operators," Journal of Convex Analysis, vol. 16, no. 2, pp. 587-600, 2009.

[13] H. K. Xu, "Iterative methods for the split feasibility problem in infinite-dimensional Hilbert spaces," Inverse Problems, vol. 26, no. 10, Article ID 105018, 2010.

[14] F. Wang and H.-K. Xu, "Cyclic algorithms for split feasibility problems in Hilbert spaces," Nonlinear Analysis: Theory, Methods \& Applications, vol. 74, no. 12, pp. 4105-4111, 2011.

[15] Z. Wang, Q. Yang, and Y. Yang, “The relaxed inexact projection methods for the split feasibility problem," Applied Mathematics and Computation, vol. 217, no. 12, pp. 5347-5359, 2011.

[16] L.-C. Ceng, Q. H. Ansari, and J.-C. Yao, "Relaxed extragradient methods for finding minimum-norm solutions of the split feasibility problem," Nonlinear Analysis: Theory, Methods \& Applications, vol. 75, no. 4, pp. 2116-2125, 2012.
[17] J. Zhao, Y. Zhang, and Q. Yang, "Modified projection methods for the split feasibility problem and the multiple-sets split feasibility problem," Applied Mathematics and Computation, vol. 219, no. 4, pp. 1644-1653, 2012.

[18] A. Moudafi, "A relaxed alternating CQ-algorithm for convex feasibility problems," Nonlinear Analysis. Theory, Methods \& Applications. An International Multidisciplinary Journal. Series A: Theory and Methods, vol. 79, pp. 117-121, 2013.

[19] Y. Yao, M. Postolache, and Y.-C. Liou, "Strong convergence of a self-adaptive method for the split feasibility problem," Fixed Point Theory and Applications, vol. 2013, article 201, 12 pages, 2013.

[20] R. Kraikaew and S. Saejung, "On split common fixed point problems," Journal of Mathematical Analysis and Applications, vol. 415, no. 2, pp. 513-524, 2014.

[21] Y. Yao, R. P. Agarwal, M. Postolache, and Y.-C. Liou, "Algorithms with strong convergence for the split common solution of the feasibility problem and fixed point problem," Fixed Point Theory and Applications, vol. 2014, article 183, 2014.

[22] B. Qu, B. Liu, and N. Zheng, "On the computation of the stepsize for the CQ-like algorithms for the split feasibility problem," Applied Mathematics and Computation, vol. 262, pp. 218-223, 2015.

[23] Q. W. Fan and X. Y. Wang, "An explicit iterative algorithm for $k$ strictly pseudo-contractive mappings in Banach spaces," Journal of Nonlinear Science and Applications, vol. 9, pp. 5021-5028, 2016.

[24] A. Moudafi, "The split common fixed-point problem for demicontractive mappings," Inverse Problems, vol. 26, no. 5, Article ID 055007, 6 pages, 2010.

[25] A. Moudafi, "A note on the split common fixed-point problem for quasi-nonexpansive operators," Nonlinear Analysis: Theory, Methods \& Applications, vol. 74, no. 12, pp. 4083-4087, 2011.

[26] H. Cui and F. Wang, "Iterative methods for the split common fixed point problem in Hilbert spaces," Fixed Point Theory and Applications, 2014:78, 8 pages, 2014.

[27] C. Byrne, Y. Censor, A. Gibali, and S. Reich, "The split common null point problem," Journal of Nonlinear \& Convex Analysis, vol. 13, no. 4, pp. 759-775, 2012.

[28] Y. Censor, A. Gibali, S. Reich, and S. Sabach, "Common solutions to variational inequalities," Set-Valued and Variational Analysis, vol. 20, no. 2, pp. 229-247, 2012.

[29] Y. Censor, A. Gibali, and S. Reich, "Algorithms for the split variational inequality problem," Numerical Algorithms, vol. 59, no. 2, pp. 301-323, 2012.

[30] H.-K. Xu, "Viscosity approximation methods for nonexpansive mappings," Journal of Mathematical Analysis and Applications, vol. 298, no. 1, pp. 279-291, 2004.

[31] K. Goebel and W. A. Kirk, Topics in Metric Fixed Point Theory, vol. 28 of Cambridge Studies in Advanced Mathematics, Cambridge University Press, Cambridge, UK, 1990.

[32] W. Takahashi, Nonlinear Functional Analysis, Yokohama Publishers, Yokohama, Japan, 2000. 


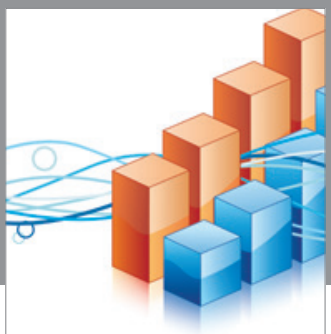

Advances in

Operations Research

vatem alat4

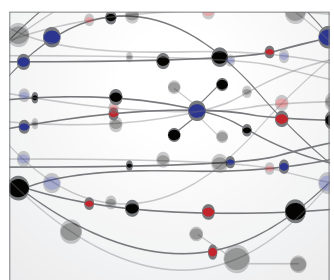

\section{The Scientific} World Journal
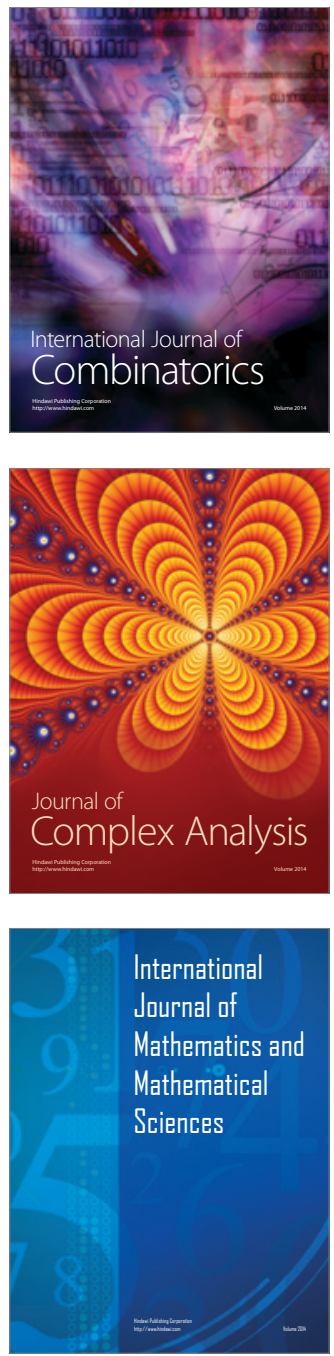
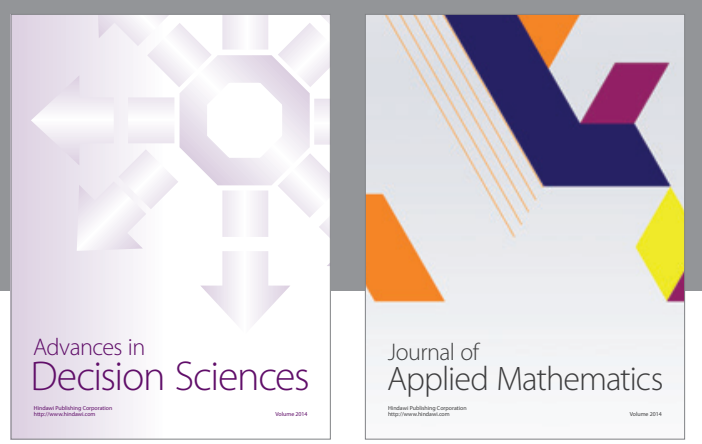

Algebra

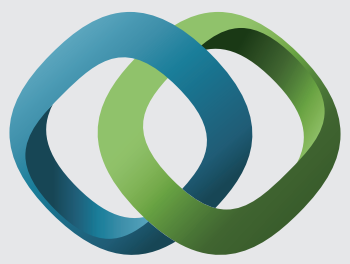

\section{Hindawi}

Submit your manuscripts at

http://www.hindawi.com
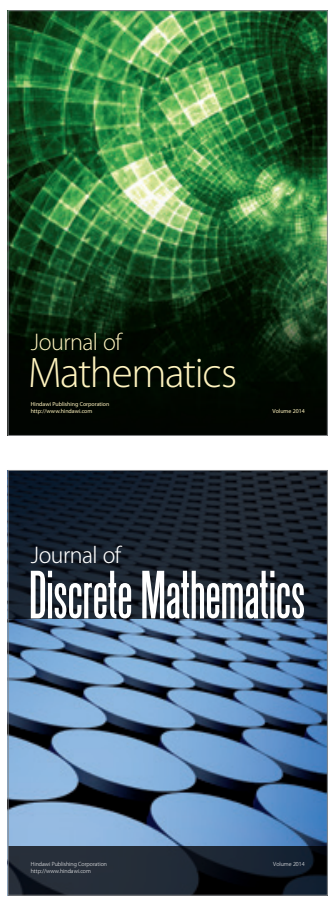

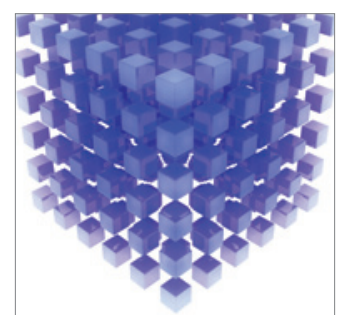

Mathematical Problems in Engineering
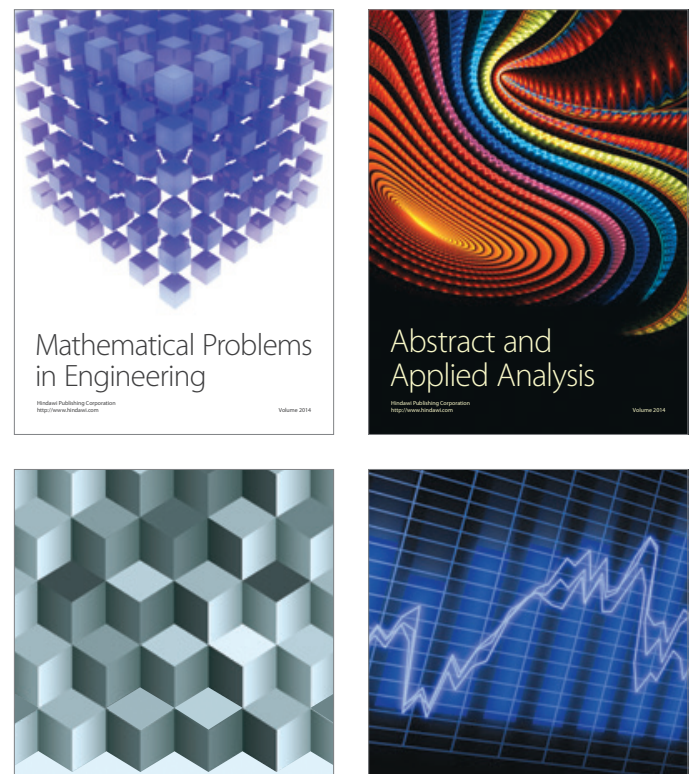

Journal of

Function Spaces

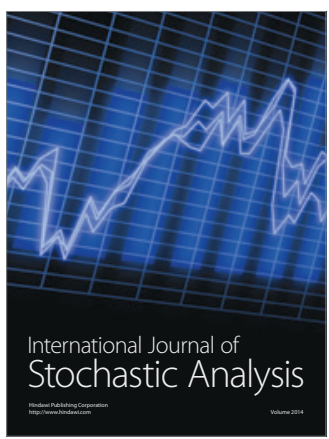

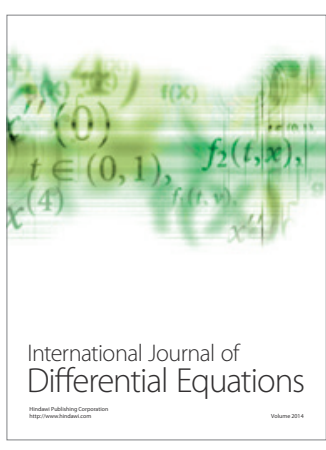
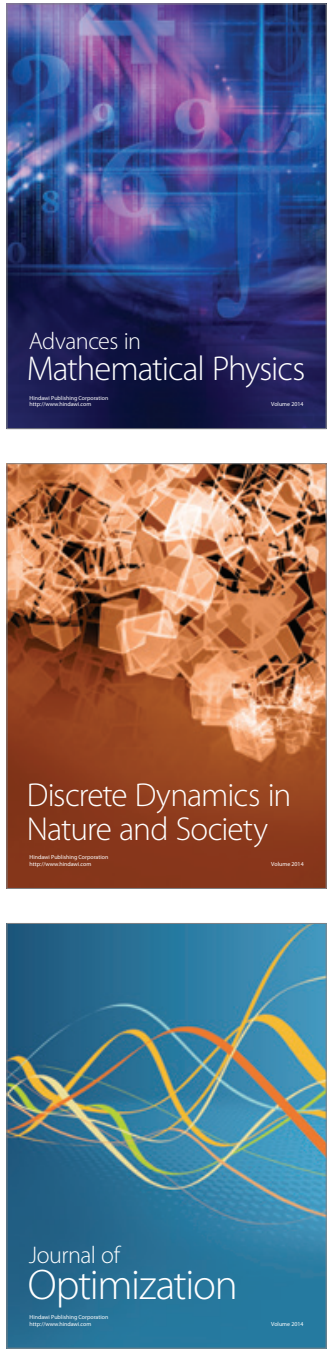